\title{
KORELASI DIAMETER SELUBUNG NERVUS OPTIK DAN MARSHALL CT SCORE DENGAN SKALA KOMA GLASGOW PADA CEDERA KEPALA
}

\author{
CORRELATION BETWEEN OPTIC NERVE SHEATH DIAMETER AND MARSHALL \\ CT SCORE WITH GLASGOW COMA SCALE IN TRAUMATIC BRAIN INJURY
}

Rani Maria Yogipranata, * Hermina Sukmaningtyas*

\section{ABSTRACT}

Introduction: In traumatic brain injury (TBI), non-contrast brain CT scan is able to detect an increase in intracranial pressure, which is crucial in patient's management. Optic nerve sheath diameter's (ONSD) measurement is a new method that is expected to assess an increase in intracranial pressure noninvasively. Marshall CT score is a valid instrument, a de facto standard to classify head injury patient which correlates with an increased intracranial pressure.

Aims: To see the correlation between ONSD and Marshall CT score with Glasgow Coma Scale (GCS).

Methods: This was a retrospective, analytic observational with cross-sectional research's design taken from the patients'medical record admitted in Dr. Kariadi Hospital, Semarang, between March-August 2017. Measurement of ONSD and Marshall CT score were done by a radiologist. Rank Spearman's were used to assess the correlation between variables.

Results: There were 34 subjects, the majority were man (67,6\%), with highest incidents in less than 30 years age $(41,2 \%)$ and mostly caused by accident (76,4\%). Statistical analysis showed a moderate negative degree correlation between ONSD and Marshall CT score with GCS.

Discussion: Enlargement of ONSD and higher Marshall CT score were correlated negatively related with the GCS in TBI patients with increased intracranial pressure.

Keywords: Glasgow Coma Scale, Marshall CT score, optic nerve sheath diameter's, traumatic brain injury

\section{ABSTRAK}

Pendahuluan: Pada cedera kepala atau traumatic brain injury (TBI), penggunaan CT scan kepala tanpa kontras dapat mendeteksi tanda-tanda peningkatan tekanan intrakranial (TIK), yang penting bagi tata laksana pasien. Sementara pengukuran diameter optic nerve sheath yang disebut optic nerve sheath diameter (ONSD) merupakan metode baru yang diharapkan dapat menilai peningkatan tekanan intrakranial secara non-invasif. Marshall CT score merupakan instrumen valid dan menjadi standar de facto dalam mengklasifikasikan pasien cedera kepala yang berkorelasi dengan peningkatan TIK.

Tujuan: Untuk melihat adanya korelasi antara diameter N. Optikus dan Marshall CT score dengan Skala Koma Glasgow (Glasgow Coma Scale/GCS).

Metode: Penelitian analitik observasional retrospektif secara potong lintang dari data rekam medis pasien cedera kepala dewasa yang dirawat di RSUP Prof. Dr. Kariadi, Semarang, pada bulan Maret-Agustus 2017. Selanjutnya kesemua subjek dilakukan pengukuran ONSD pada kedua mata serta penilaian Marshall CT score oleh seorang spesialis radiologi. Dilakukan uji korelasi Rank Spearman's untuk menilai ketiga parameter tersebut.

Hasil: Terdapat 34 subjek yang terutama laki-laki $(67,6 \%)$ dengan usia terbanyak $<30$ tahun $(41,2 \%)$ dan penyebab terbanyak adalah kecelakaan $(76,4 \%)$. Didapatkan korelasi negatif derajat sedang antara ONSD dan Marshall CT score dengan GCS.

Diskusi: Peningkatan diameter optic nerve sheath dan Marshall CT score berkorelasi dengan penurunan skor GCS pada pasien cedera kepala yang mengalami peningkatan TIK.

Kata kunci: Cedera kepala, diameter optic nerve sheath, Marshall CT score, Skala Koma Glasgow

*Departemen Radiologi FK Universitas Diponegoro/RSUP Dr. Kariadi, Semarang. Korespondensi: raniyogipranata@gmail.com.

\section{PENDAHULUAN}

Cedera kepala atau traumatic brain injury (TBI) merupakan masalah kesehatan dan sosioekonomi yang utama. ${ }^{1-2}$ Dengan insiden yang tinggi, cedera kepala merupakan salah satu penyebab morbiditas dan mortalitas pada kelompok usia muda $<45$ tahun. ${ }^{3}$ Hal ini terutama ditemukan pada populasi Asia (344/100.000 penduduk) dibandingkan Eropa
(235/100.000 penduduk) maupun Amerika Serikat $(103 / 100.000) .^{4-5}$ Sebanyak $40 \%$ penderita yang berhasil selamat dari cedera kepala memiliki sekuele jangka panjang serta disabilitas yang akan menjadi beban ekonomi serta menghambat kualitas hidup. ${ }^{2,6-7}$

Tata laksana yang tepat secara bermakna mengurangi morbiditas dan mortalitas, mengurangi kunjungan rumah sakit dan biaya kesehatan., ${ }^{2,7}$ 
Pemeriksaan CT scan kepala tanpa kontras berperan penting dalam tata laksana cedera kepala akut untuk menentukan ada dan luasnya cedera, serta perencanaan bedah dan intervensi invasif lainnya. ${ }^{8} \mathrm{CT}$ scan menjadi pilihan modalitas utama berdasarkan appropriateness criteria (ACR) karena pemeriksaannya yang cepat, banyak tersedia, dan sensitif dalam menunjukkan cedera struktural, serta penting dalam membantu menentukan prognosis luaran pasien. ${ }^{9-10}$

Pada cedera kepala terjadi dua tahapan mekanisme cedera, yaitu cedera primer (primary insults) yang terjadi pada saat kecelakaan dan cedera sekunder (secondary insults) yang merupakan kerusakan non-mekanik dan kelanjutan proses patologis saat terjadi cedera. Cedera sekunder menyebabkan edema vasogenik dan sitotoksik serta mengakibatkan peningkatan tekanan intrakranial (TIK). Proses cedera sekunder terus berjalan, sehingga tindakan intervensi dini terhadap proses ini dapat memperbaiki prognosis pasien., 3

Secara klinis, tanda-tanda peningkatan TIK dapat dinilai menggunakan Skala Koma Glasgow (SKG) atau Glasgow Coma Scale (GCS). Pada kondisi peningkatan TIK atau beratnya kelainan yang diderita, maka skor SKG akan semakin rendah dan kondisi pasien semakin buruk. ${ }^{3,9}$ Penelitian Novkoski M dkk, membuktikan adanya korelasi antara peningkatan TIK dengan penurunan SKG. ${ }^{11}$ Oleh karena itu diperlukan pengukuran peningkatan TIK yang bersifat non-invasif, antara lain menggunakan Marshall CT score. Instrumen ini valid dan menjadi standar de facto dalam mengklasifikasikan pasien cedera kepala berdasarkan gambaran CT scan dan berkorelasi dengan peningkatan TIK. ${ }^{9,12-13}$

Pengukuran diameter selubung N. Optik (optic nerve sheath diameter's/ONSD) merupakan metode baru bagi pengukuran TIK non-invasif. ${ }^{7,14-18}$ ONSD terpilih menjadi salah satu indikator peningkatan TIK karena bersifat stabil dan konstan pada TIK yang normal, serta memiliki korelasi linear dengan peningkatan TIK. ${ }^{19-20}$ Kompleks selubung N. Optik memiliki ruang subaraknoid yang berhubungan langsung dengan ruang subaraknoid sisterna kiasma otak, sehingga terjadi transfer bebas cairan serebrospinal diantara dua kompartemen tersebut. Proses tersebut menjelaskan adanya tekanan yang sama diantara dua kompartemen tersebut (Gambar 1). ${ }^{18}$

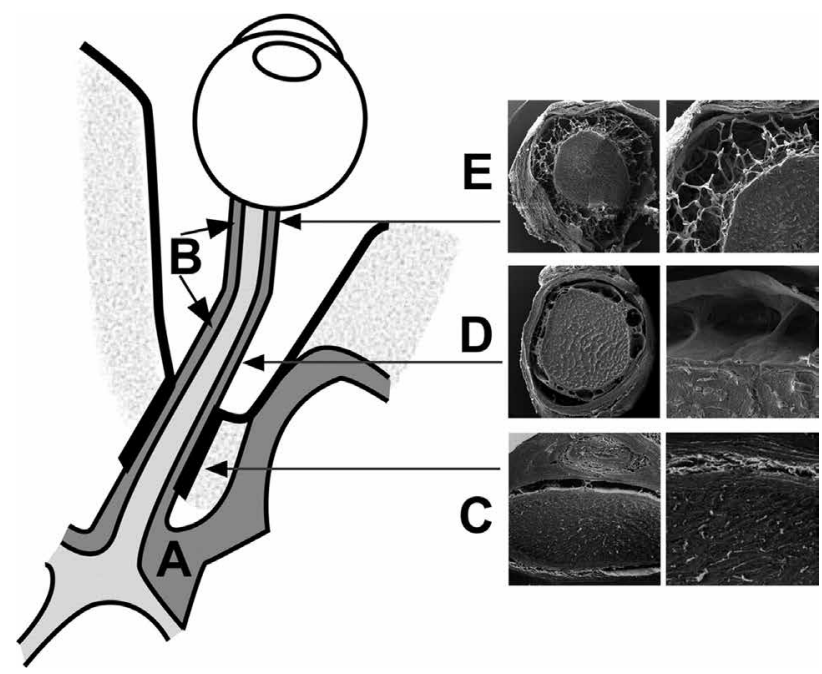

Gambar 1. Ilustrasi Ruang Cairan Serebrospinal yang Mengelilingi Kiasma Optik

Ruang cairan serebrospinal intrakranial (A) dan cairan serebrospinal mengelilingi nervus optikus (ruang serebrospinal orbita) (B), ruang subaraknoid paling sempit pada regio kanalikular (C), ruang subaraknoid segmen intraorbital memiliki banyak septa (D), sementara ruang subaraknoid segmen retrobulbar memiliki trabekula-trabekula kecil (E). ${ }^{18}$

Pengukuran ONSD dapat dilakukan secara ultrasonografi maupun CT scan, ${ }^{14}$ namun CT scan lebih superior karena sederhana, mudah, dan objektif, serta dapat dilakukan bersamaan dengan CT scan kepala pasien cedera kepala. Adapun keterbatasan menggunakan ultrasonografi karena operator dependen. ${ }^{14,16,19}$

Diameter ONSD tidak dipengaruhi oleh jenis kelamin, usia, berat badan, tinggi badan, dan mata kanan atau kiri. ${ }^{22-23}$ Pasien dengan kavum orbita normal dan tidak memiliki kelainan endokrin menunjukkan nilai normal optic nerve sheath complex 3,2-5,6mm. ${ }^{26}$ Geeraerts dkk dan Soldatos dkk menyarankan nilai batas (cutoff) untuk memprediksi peningkatan TIK adalah $5,7 \mathrm{~mm} .{ }^{15,18}$

Abdalla dkk, Legrand dkk, dan Sekhon dkk, menunjukkan adanya korelasi bermakna antara ONSD dengan menggunakan ultrasonografi maupun CT scan pada peningkatan TIK. ${ }^{7,14,17,19}$ Adanya korelasi dari parameter-parameter dapat membantu tata laksana pasien cedera kepala dalam memantau TIK secara non-invasif. 


\section{TUJUAN}

Menemukan hubungan antara ONSD dan Marshall CT score dengan SKG terkait peningkatan TIK.

\section{METODE}

Penelitian analitik observasional retrospektif secara potong lintang dari data rekam medis pasien cedera kepala dewasa yang dirawat di RSUP Dr. Kariadi, Semarang pada bulan Maret-Agustus 2017. Kriteria eksklusi adalah trauma pada wajah yang mengenai orbita dan atau bola mata, memiliki kelainan pada mata yang memengaruhi nervus optikus dan kavum orbita, riwayat operasi untuk trauma kepala, riwayat stroke, tumor, atau infeksi intrakranial, serta pemeriksaan CT scan kepala tanpa kontras lebih dari 24 jam setelah trauma kepala.

Pemeriksaan CT scan menggunakan alat MSCT Siemens SOMATOM Sensation 64 Slice dengan protokol CT scan kepala tanpa kontras (kVA 120, mAs 380, dan ketebalan potongan $0,6 \mathrm{~mm}$ ). Dilakukan pengukuran diameter selubung N. Optik dan Marshall CT score dari arsip data CT scan di bagian Radiologi RSDK oleh seorang dokter spesialis Radiologi.

Diameter selubung N. Optik kedua mata diukur menggunakan Syngo viewer pada window width 350 dan window level 40 pada potongan aksial sejajar dengan sumbu N. Optikus, dengan jarak $3 \mathrm{~mm}$ di belakang batas posterior bola mata (Gambar 2). Selanjutnya dihitung nilai rerata ONSD kanan-kiri untuk setiap subjek. Nilai normal ONSD adalah 3,2$5,6 \mathrm{~mm}$ dan dinyatakan abnormal jika $\geq 5,7 \mathrm{~mm}$.

Marshall CT score mengukur status sisterna mesensefalik, derajat pergesaran garis tengah (midline shifting), dan perdarahan intrakranial pada CT scan kepala tanpa kontras. Volume perdarahan dihitung menggunakan volume tool application pada Syngo viewer dengan Hounsfield unit (HU) ditentukan 50-90 HU. Hasil penilaian diklasifikasikan menjadi Marshall score 1 sampai 6 (Tabel 1). ${ }^{14}$

Skor SKG diambil dari data rekam medis subjek saat di instalasi gawat darurat, diklasifikasikan

Tabel 1. Klasifikasi CT dari Marshall ${ }^{14}$

\begin{tabular}{|c|c|c|}
\hline Skor & Kategori & Definisi \\
\hline 1 & Diffuse Injury I & Tak tampak kelainan patologis intrakranial pada CT scan \\
\hline 2 & Diffuse Injury II & $\begin{array}{l}\text { Sisterna masih tampak baik disertai midline shifting } 0-5 \mathrm{~mm} \text { dan atau adanya } \\
\text { lesi; tidak terdapat perdarahan intrakranial }>25 \mathrm{ml} \text { dengan atau tanpa disertai } \\
\text { fraktur os kalvaria atau benda asing }\end{array}$ \\
\hline 3 & $\begin{array}{l}\text { Diffuse Injury III } \\
\text { (pembengkakan) }\end{array}$ & $\begin{array}{l}\text { Sisterna menyempit atau obliterasi dengan midline shifting } 0-5 \mathrm{~mm} \text {; tidak } \\
\text { terdapat perdarahan intrakranial }>25 \mathrm{ml}\end{array}$ \\
\hline 4 & Diffuse Injury IV (shift) & Midline shifting $>5 \mathrm{~mm}$; tidak terdapat perdarahan intrakranial $>25 \mathrm{ml}$ \\
\hline 5 & Evakuasi massa & Berbagai lesi yang dilakukan tindakan operatif \\
\hline 6 & Massa tidak dievakuasi & Perdarahan intrakranial dengan volume $>25 \mathrm{ml}$; tidak dilakukan tindakan operatif \\
\hline
\end{tabular}

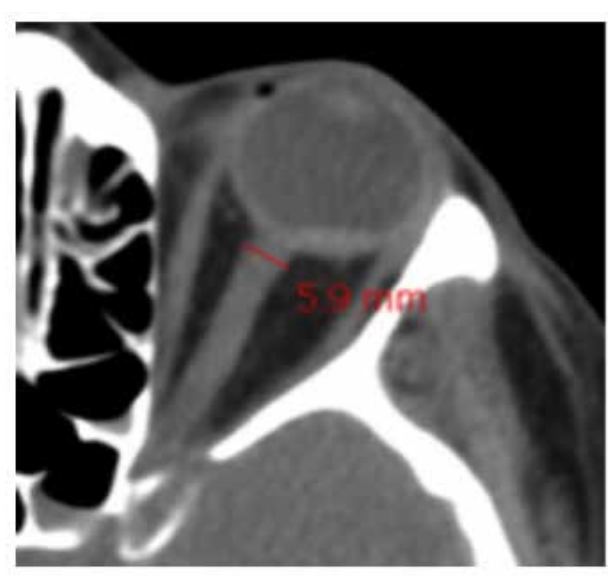

Gambar 2. Metode Pengukuran Diameter Selubung N. Optik pada CT Scan Kepala Tanpa Kontras ${ }^{16}$ menjadi cedera kepala ringan (CKR) jika SKG 1415, cedera kepala sedang (CKS) jika SKG 9-13, dan cedera kepala berat $(\mathrm{CKB})$ jika $\mathrm{SKG} \leq 8 .{ }^{24}$ Analisis data menggunakan program statistik SPSS, uji korelasi non-parametrik Rank Spearman's pada $\alpha=5 \%$.

\section{HASIL}

Selama periode penelitian terkumpul sebanyak 110 pasien cedera kepala, namun hanya 34 orang yang dapat dijadikan subjek penelitian (Tabel 2). Mayoritas subjek adalah laki-laki $(67,6 \%)$ berusia $<30$ tahun $(41,2 \%)$ akibat kecelakaan lalu-lintas 
(76,4\%). Subjek juga terutama menderita cedera kepala ringan dan sedang (masing-masing 44,1\%) dengan nilai ONSD yang abnormal $(61,8 \%)$ dan Marshall CT score $5(29,4 \%)$.

Tabel 2. Karakteristik Subjek Penelitian $(n=34)$

\begin{tabular}{|c|c|}
\hline Karakteristik & n (\%) \\
\hline \multicolumn{2}{|l|}{ Usia } \\
\hline - $<30$ thn & $14(41,2)$ \\
\hline - $31-50$ & $8(23,5)$ \\
\hline - $>50$ tahun & $12(35,3)$ \\
\hline \multicolumn{2}{|l|}{ Jenis kelamin } \\
\hline - Laki-laki & $23(67,6)$ \\
\hline - Perempuan & $11(32,4)$ \\
\hline Penyebab trauma & $26(76,5)$ \\
\hline \multicolumn{2}{|l|}{ - KLL } \\
\hline - Non-KLL (assault) & $6(17,6)$ \\
\hline - Jatuh & $2(5,9)$ \\
\hline \multicolumn{2}{|l|}{ SKG } \\
\hline - Cedera kepala berat & $4(11,8)$ \\
\hline - Cedera kepala sedang & $15(44,1)$ \\
\hline - Cedera kepala ringan & $15(44,1)$ \\
\hline \multicolumn{2}{|l|}{ ONSD } \\
\hline - Normal & $13(38,2)$ \\
\hline - Abnormal & $21(61,8)$ \\
\hline \multicolumn{2}{|l|}{ Marshall CT score } \\
\hline - Skor 1 & $6(17,6)$ \\
\hline - Skor2 & $9(26,5)$ \\
\hline - Skor3 & $7(20,6)$ \\
\hline - Skor4 & $0(0)$ \\
\hline - Skor5 & $10(29,4)$ \\
\hline - Skor6 & $2(5,9)$ \\
\hline
\end{tabular}

KLL: kecelakaan lalu lintas; SKG: Skala Koma Glasgow; ONSD: optic nerve sheathdiameter.

Tabel 3 menunjukkan seluruh subjek dengan CKB (100\%) memiliki ukuran diameter selubung N. Optik yang lebih besar dari normal, demikian pula pada mayoritas subjek dengan CKS (93\%). Adapun subjek dengan CKR kebanyakan memiliki diameter selubung N. Optik yang normal (80\%).

Uji korelasi menunjukkan adanya korelasi negatif derajat sedang antara ONSD dengan SKG $(\mathrm{p}=0,002$; rho $=-0,509)$ dan antara Marshall CT score dengan SKG $(p=0,003$; rho $=0,494)$. Semakin besar diameter selubung N. Optik dan semakin tinggi Marshall CT score, maka nilai SKG akan semakin rendah.
Tabel 3. Diameter Selubung Nervus Optik berdasarkan Jenis Cedera Kepala $(n=34)$

\begin{tabular}{lcc}
\hline \multirow{2}{*}{ Jenis Cedera } & \multicolumn{2}{c}{ ONSD } \\
\cline { 2 - 3 } & Normal & Abnormal \\
\cline { 2 - 3 } & $\mathbf{n ~ ( \% )}$ & $\mathbf{n ~ ( \% )}$ \\
\hline Cedera kepala berat & $0(0)$ & $4(100)$ \\
Cedera kepala sedang & $1(7)$ & $14(93)$ \\
Cedera kepala ringan & $12(80)$ & $3(20)$ \\
\hline
\end{tabular}

Uji korelasi; ONSD: optic nerve sheathdiameter.

\section{PEMBAHASAN}

Diameter selubung N. Optik meningkat seiring dengan beratnya cedera kepala penderita. Hasil penelitian menunjukkan pelebaran ONSD pada $100 \%$ pasien CKB, $93 \%$ pasien CKS dan hanya $20 \%$ pasien CKR. Hal ini sesuai dengan Sekhon dkk dan Legrand dkk bahwa pada kondisi terjadi peningkatan TIK, maka ONSD akan melebar. ${ }^{7,14,19}$

Pada penelitian ini didapatkan korelasi negatif derajat sedang antara ONSD dengan SKG, dan Marshall CT score dengan SKG, sesuai dengan Novkoski $\mathrm{M}$ dkk, adanya korelasi antara peningkatan TIK dengan status klinis pasien yang dinilai dalam bentuk SKG. ${ }^{11}$ Sekhon MS dkk dan Legrand dkk, menunjukkan korelasi kuat antara peningkatan TIK dan ONSD, serta membuktikan bahwa ONSD merupakan prediktor yang lebih baik daripada gambaran CT lainnya.,14,19 Waqas dkk tidak mendapatkan korelasi antara ONSD dengan skor SKG, namun keterbatasannya adalah tidak mendapatkan pasien cedera kepala $(<4$ jam $)$ seperti pada penelitian Legrand dkk. ${ }^{16}$

Hasil penelitian ini didapatkan korelasi negatif derajat sedang antara ONSD dengan SKG karena penelitian ini mengukur ONSD pada penderita CKR, CKS, dan CKB. Adanya korelasi kuat antara peningkatan TIK dan ONSD pada penelitian Sekhon MS dkk dan Legrand dkk dapat disebabkan karena kedua penelitian tersebut hanya mengambil pasien dengan CKB saja.

Penelitian ini tidak mendapatkan subjek klasifikasi Marshall CT score 4 (Tabel 4), karena pasien dengan Marshall CT score 4 dilakukan tindakan operatif, sehingga dimasukkan ke dalam Marshall CT score 5. Deepika dkk menyatakan bahwa pada praktiknya keputusan untuk dilakukannya 
Tabel 4. Marshall CT Score pada Jenis Cedera Kepala

\begin{tabular}{lllllll}
\hline \multirow{2}{*}{$\begin{array}{c}\text { Jenis Cedera } \\
\text { Kepala }\end{array}$} & \multicolumn{6}{c}{ Marshall CT Score } \\
\cline { 2 - 7 } & $\mathbf{1}$ & $\mathbf{2}$ & $\mathbf{3}$ & $\mathbf{4}$ & $\mathbf{5}$ & $\mathbf{6}$ \\
\hline Cedera kepala berat & 0 & 1 & 1 & 0 & 1 & 1 \\
Cedera kepala sedang & 0 & 4 & 4 & 0 & 6 & 1 \\
Cedera kepala ringan & 6 & 4 & 2 & 0 & 3 & 0 \\
\hline
\end{tabular}

operasi tidak tergantung pada jumlah perdarahan dan midline shifting, namun pada kondisi klinis pasien serta keputusan masing-masing ahli bedah saraf. ${ }^{13}$

Marshall CT score 5 yang didapatkan pada 3 penderita CKR (30\%) (Tabel 4) semuanya disebabkan oleh non-KLL (penyerangan). Berdasarkan patofisiologi cedera kepala, efek cedera primer pada otak tergantung dari sifat trauma (mekanisme cedera, gaya, dan arah benturan). Pola kontusio tergantung gerakan kepala pada saat benturan dan pemakaian pelindung kepala. ${ }^{25}$ Cedera yang terjadi pada kecepatan tinggi biasanya menghasilkan cedera lebih berat.

Percobaan menunjukkan bahwa akselerasi rotasional dapat menghasilkan cedera axonal, sementara akselerasi linear saja hanya menyebabkan kontusio dan perdarahan subdural, tanpa kehilangan kesadaran. ${ }^{26}$ Mekanisme trauma tersebut dapat menjelaskan subjek dengan Marshall CT score 5 namun diklasifikasikan dalam kategori CKR, yaitu cedera akibat non-KLL (penyerangan) hanya memberikan gaya akselerasi linear dan tidak terjadi akselerasi rotasional yang dapat menyebabkan kehilangan kesadaran.

Keterbatasan penelitian ini karena tidak melihat penyebab cedera kepala sebagai faktor yang dapat memengaruhi ONSD, Marshall CT score, dan SKG, oleh karena ada perbedaan antara pasien dengan mekanika trauma akselerasi deselerasi yang memiliki kecepatan tinggi, dengan mekanika trauma lain (contoh: dipukul). Keterbatasan lainnya adalah penelitian ini hanya menilai peningkatan tekanan intrakranial berdasarkan gambaran CT scan dengan menggunakan Marshall CT score dan tidak melakukan penilaian klinis bahwa subjek memang mengalami peningkatan tekanan intrakranial.

\section{KESIMPULAN}

ONSD dan Marshall CT score memiliki korelasi negatif derajat sedang dengan SKG, yang berarti pasien cedera kepala yang mengalami peningkatan TIK akan mendapat skor SKG yang semakin rendah serta ONSD dan Marshall CT score yang semakin tinggi.

\section{DAFTAR PUSTAKA}

1. Institute for Health Metrics and Evaluation. The global burden of disease: generating evidence, guiding policy. Seattle: IHME; 2013.

2. Dinsmore J. Traumatic brain injury: an evidencebased review of management. Continuing Education in Anaesthesia: Critical Care \& Pain. 2013;13(6):18995.

3. Werner C, Engelhard K. Pathophysiology of traumatic brain injury. Br J Anaesth. 2007;99(1):4-9.

4. Raj R. Prognostic models in traumatic brain injury [disertasi]. Helsinski: Helsinski University Central Hospital dan University of Helsinski; 2014.

5. Peeter W, Brande R, Polinder S, Brazinova A, Steyerberg EW, Lingsma HF, dkk. Epidemiology of traumatic brain injury in europe. Acta Neurochir. 2015;157(10):1683-96.

6. Oliveira RA, Araujo S, Falcao ALE, Soares S, Kosour C, Dragosavac D, dkk. Glasgow outcome scale at hospital discharge as a prognostic index in patients with severe traumatic brain injury. Arq Neuropsiquiatr. 2012;70(8):604-8.

7. Sekhon MS, McBeth P, Zou J, Qiao L, Kolmodin L, Henderson WR, Reynolds S, Griesdale DE. Association between optic nerve sheath diameter and mortality in patients with severe traumatic brain injury. Neurocritical Care. 2014;21(2):245-52.

8. Lee B, Newberg A. Neuroimaging in traumatic brain imaging. NeuroRx. 2005;2(2):372-83.

9. Moppett IK. Traumatic brain injury: assessment, resuscitation and early management. British J Anaesth. 2007;99(1):18-31.

10. American College of Radiology. ACR appropriateness criteria head trauma. ACR. 2012;2012:1-6.

11. Novkoski M, Gvozdenovic A, Kelecic M, Gopcevic A, Mazul-Sunko B, Siranovic M. Correlation between skala koma glasgowscore and intracranial pressure in patients with severe head injury. Acta Clin Croat. 2001;40:191-5.

12. Marshall LF, Marshall SB, Klauber MR, Clark MB, Eisenberg HM, Jane JA, dkk. A new classification of head injury based on computerized tomography. J Neurosurg. 1991;75(1s):S14-20.

13. Deepika A, Prabhuraj AR, Saikia A, Shukla D. Comparison of predictability of Marshall and Rotterdam CT scan scoring system in determining early mortality after traumatic brain injury. Acta Neurochirurgica. 2015;157(11):2033-8. 
14. Legrand A, Jeanjean P, Delanghe F, Peltier J, Lecat B, Dupont H. Estimation of optic nerve sheath diameter on an initial brain computed tomography scan can contribute prognostic information in traumatic brain injury patients. Crit Care. 2013;17(2):R61.

15. Sahoo SS, Agrawal D. Correlation of optic nerve sheath diameter with intracranial pressure monitoring in patients with severe traumatic brain injury. Indian J Neurotrauma. 2013;10(1):9-12.

16. Waqas M, Bakhshi SK, Shamim MS, Anwar S. Radiological prognostication in patients with head trauma requiring decompressive craniectomy: analysis of optic nerve sheath diameter and Rotterdam CT scoring system. J Neuroradiol. 2016;43(1):25-30.

17. Abdalla A, Beshey B, Abougabal A, Elzahaby K. Value of ultrasonographic optic nerve sheath diameter in assessing increased intracranial pressure in patients with moderate to severe traumatic brain injury. Intensive Care Med Exp. 2015;3(Supl 1):A488.

18. Soldatos T, Chatzimichail K, Papathanasiou M, Gouliamos A. Optic nerve sonography: a new window for the non-invasive evaluation of intracranial pressure in brain injury. Emerg Med J. 2009;26(9):630-4.

19. Sekhon MS, Griesdale DE, Robba C, McGlashan $\mathrm{N}$, Needham E, Walland K, dkk. Optic nerve sheath diameter on computed tomography is correlated with simultaneously measured intracranial pressure in patients with severe traumatic brain injury. Intensive Care Med. 2014;40(9):1267-74.
20. Rosenberg JB, Shiloh AL, Savel RH, Eisen LA. Noninvasive methods of estimating intracranial pressure. Neurocritical Care. 2011;15(3):599-608

21. Killer H, Jaggi G, Flammer J, Miller N, Huber A, Mironov A. Cerebrospinal fluid dynamics between the intracranial and the subarachnoid space of the optic nerve. Is it always bidirectional? Brain. 2007;130(Pt 2):514-20

22. Chen H, Ding GS, Zhao YC, Yu RG, Zhou JX. Ultrasound measurement of optic nerve diameter and optic nerve sheath diameter in healthy Chinese adults. BMC Neurol. 2015;15(1):106.

23. Ariyurek M, Ozgen A. Normative measurements of orbital structure using CT. AJR Am J Roentgenol. 1998;170(4):1093-6.

24. Mena JH, Sanchez AI, Rubiano AM, Peitzman AB, Sperry JL, Gutierrez MI, dkk. effect of the modified glasgow coma scale score criteria for mild traumatic brain injury on mortality prediction: comparing classic and modified glasgow coma scale score model scores of 13. J Trauma. 2011;71(5):1185-93.

25. Fink KR. Pathophysiology of traumatic brain injury and impact on management. Dalam: Anzai Y, Fink KR. Imaging of traumatic brain injury. New York: Thieme Medical Publisher; 2015. h. 35-46.

26. Blyth BJ, Bazarian JJ. Traumatic alterations in consciousness: traumatic brain injury. Emerg Med Clin North Am. 2010;28(3):571-94. 